20. Yavin, E., and Menkes, J. H.: Glyceride metabolism in cultured cells dissociated from rat cerebral cortex. J. Neurochem., 21: 901 (1973).

21. New England Nuclear, Boston, Mass.

22. Pentex Miles Lab, Kanakee, III.

23. Reheis Chemical Co., Chicago, Ill.

24. Analtech, Canoga Park, Calif.

25. Supelco, Inc., Bellefonte, $\mathrm{Pa}$.

26. Consent to study the children was provided by the parents in all cases.

27. The current address of Dr. E. Yavin is: Biochemistry Department, The Weizman

Copyright $\odot 1976$ International Pediatric Research Foundation, Inc.
Institute of Science, Rehovot, Israel.

28. The current address of Dr. A. H. Nash is: 9615 Brighton Way, Beverly Hills, Calif.

29. This work was supported in part by United States Public Health Service 1-P01-HD05515-01, 1-R01-HD09281-01, and 1-T32-GM07015-01.

30. Requests for reprints should be addressed to: A. Milunsky, MB.Ch., M.R.C.P.,

D.C.H., Genetics Laboratory, Eunice Kennedy Shriver Center, 200 Trapelo Road, Waltham, Massachusetts 02154 (USA).

31. Accepted for publication December 3, 1975.

Pediat. Res. 10: 545-550 (1976)

Fetus

lung

methionine adenosyltransferase transmethylation transsulfuration

Printed in U.S.A

\title{
Methionine Adenosyltransferase and Transmethylation in Fetal and Neonatal Lung of the Human, Monkey, and Rabbit
}

\author{
HANS J. STERNOWSKY, NIELS C. R. RÄIHÄ, AND GERALD GAULL(44)
}

Department of Pediatric Research, New York State Institute for Basic Research in Mental Retardation, Staten Island, New York; Department of Pediatrics and Clinical Genetics Center, Mount Sinai School of Medicine of the City University of New York, New York, USA; Departments of Medical Chemistry and Obstetrics and Gynecology, University of Helsinki, Helsinki, Finland

\section{Extract}

Optimal conditions for the assay of methionine adenosyltransferase in crude extracts of human fetal lung were determined. Maximal activity was obtained with $36 \mathrm{mM}$ ATP, $20 \mathrm{mM}$ L-methionine, $240 \mathrm{mM} \mathrm{Mg++}$, and $160 \mathrm{mM} \mathrm{K}{ }^{+}$. The $\mathrm{pH}$ optimum was 6.2-6.4, which is the same as that for adult human lung but lower than that for human liver. In human fetal iung, there was an increase in specific activity of methionine adenosyltransferase with increasing gestational age $(r=0.87 ; P<0.01)$ up to 25 weeks of gestation, after which time no fetal specimens were obtained. The specific activity of 5-methyltetrahydrofolate-homocysteine methyltransferase of human fetal lung was $2.51 \pm 0.88 \mathrm{nmol} / \mathrm{mg}$ $\mathrm{protein} / \mathrm{hr}$, which was higher $(P<\mathbf{0 . 0 0 1})$ than the activity found in newborn lung $\left(0.14_{ \pm} 0.01\right)$. Activity of serine hydroxymethyltransferase and of betaine-homocysteine methyltransferase was absent from human fetai lung. Activity of cystathionine synthase was absent from fetal, neonatal, and mature human lung. Activity of cystathionase in fetal and newborn human lung was present only in trace amounts. In rhesus monkey lung, beginning 15 days before term, the activity of methionine adenosyltransferase increased 6-fold to reach a maximum before term ( 165 days), and during the first weeks of life the activity gradually diminished. 5-Methyltetrahydrofolate-homocysteine methyltransferase activity in fetal $(100-145$ days $)$ monkey lung was higher $(6.57 \pm 0.95 \mathrm{nmol} / \mathrm{mg}$ protein/hr) than in newborn lungs $(1.91 \pm 0.97)(P<\mathbf{0 . 0 0 1})$. In fetal rabbit lung, the activity of methionine adenosyltransferase decreased 2.5-fold during the last third of pregnancy, whereas a 2-fold increase occurred during the first $\mathbf{4 8} \mathbf{~ h r}$ after term birth.

\section{Speculation}

The increasing specific activity of methionine adenosyltransferase in the lung of the human, monkey, and rabbit around the time when extrauterine survival is possible in each species suggests that this enzyme may be important in the synthesis of surface-active lecithin and/or in methylation reactions related to detoxification of the constituents in the blood perfusing the breathing lung.

$S$-Adenosylmethionine, a major donor of methyl groups in mammalian tissues, is formed from L-methionine and ATP in the presence of $\mathrm{Mg}^{++}$and $\mathrm{K}^{+}$by methionine adenosyltransferase (ATP:L-methionine $S$-adenosyltransferase, EC. 2.5.1.6) (2). Biosynthesis of $S$-adenosylmethionine is also the first step on the transsulfuration pathway, which transfers the sulfur atom from L-methionine to the 3-carbon skeleton of L-serine to form L-cysteine. In human fetal liver and brain, but not in kidney, the transsulfuration pathway (see Fig. 1) is incomplete $(12,24,28)$ as a result of the absence of cystathionase (L-cystathionine cysteinelyase (deaminating), EC. 4.2.1.1), the enzyme which cleaves cystathionine to cysteine and $\alpha$-ketobutyrate.

In the human, the transsulfuration pathway apparently becomes active after birth (30). In the mature human, $90 \%$ of the methionine sulfur goes down this pathway (26); therefore, we examined some of the enzymes of transsulfuration and related reactions in human fetal tissues. Investigation of the remethylation of homocysteine to methionine by the vitamin $\mathbf{B}_{12}$-dependent 5-methyltetrahydrofolate-homocysteine methyltransferase (5methyltetrahydropteroyl-L-glutamate:L-homocysteine $S$-methyltransferase, EC. 2.1.1.13) demonstrated that the specific activity of this enzyme was much greater in fetal human liver and brain than in mature human liver and brain (14). The alternative enzyme for remethylation of homocysteine to methionine, betaine-homocysteine methyltransferase (EC. 2.1.1.5), was much less active (14). In addition, the apparent $\mathrm{K}_{\mathrm{m}}$ for 5-methyltetrahydrofolate-homocysteine methyltransferase is of the order of $10^{-5} \mathrm{M}$, whereas that of 
cystathionine synthase, the enzyme which competes for the substrate, homocysteine, is of the order of $10^{-3} \mathrm{M}$ (7). Furthermore, the specific activity of cystathionine synthase also is reduced in human fetal liver and brain (12). Thus, 5-methyltetrahydrofolate-homocysteine methyltransferase would be expected to compete effectively with cystathionine synthase for the free homocysteine, thus forming a methionine cycle (Fig. 1).

The methionine cycle, the existence of which has been appreciated in mature tissues $(7,9)$, was postulated to be especially active in human fetal liver and brain $(10,11)$. An active methionine cycle would conserve the sulfur of homocysteine at the price of making cyst(e)ine essential and would facilitate the biosynthetic reactions related to this cycle. The fact that cystathionase is virtually absent would, according to this hypothesis, maximize the conservation of homocysteine sulfur, since none could be converted to cysteine. We have provided ancillary evidence in support of the biologic significance of increased activity of the methionine cycle in fetal liver. (l) There is greater incorporaton of $\left[{ }^{35} \mathrm{~S}\right]$ methionine into proteins of human fetal liver than into proteins of mature human liver (12). (2) There is virtually no incorporation of the sulfur of methionine into the sulfur of cyst(e)ine by perfused human fetal liver (12). (3) There is a greater synthesis of polyamines from $S$-adenosylmethionine in fetal human liver than in mature human liver (28). (4) In fetal human liver, at the time that activity of 5-methyltetrahydrofolate-homocysteine methyltransferase is high, there is more rapid transfer of the $\beta$-carbon of serine into the de novo synthesis of DNA via thymidylate (31) than there is in adult human liver.

This cycle also seems to provide the potential for an increased enzymatic capacity for biologic methylation. Although the specific activity of methionine adenosyltransferase in human fetal liver during the second trimester is less than that of mature human liver, the specific activity of this enzyme in human fetal brain increases during the second trimester (12), and in the rat (3) it increases greatly in the liver at the time of maximal fetal growth, i.e., late in gestation. The so-called methylation pathway for synthesis of the surface-active phospholipid, phosphatidyl choline (lecithin), is considered by some investigators to be of importance in allowing

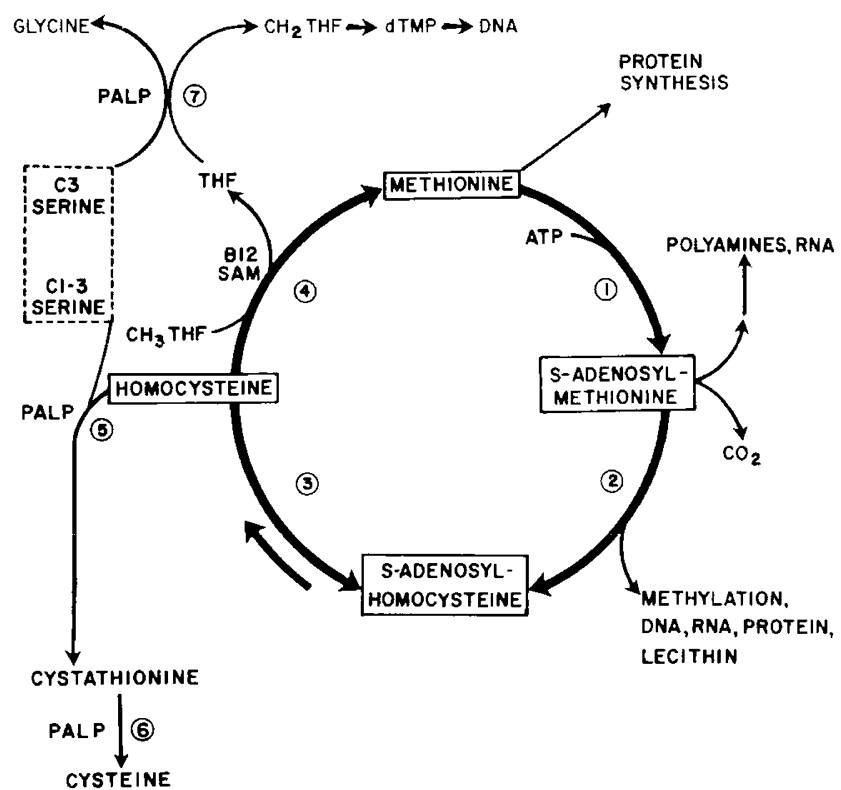

Fig. 1. The methionine cycle and related biosynthetic pathways. $\mathrm{CH}_{3} \mathrm{THF}$ : 5-methyltetrahydrofolate; $\mathrm{THF}$ : tetrahydrofolate; $\mathrm{CH}_{2} \mathrm{THF}$. 5,10-methylenetetrahydrofolate; $d T M P$ : thymidylate; $B_{12}$, vitamin $\mathrm{B}_{12}$ in cofactor form; $P A L P$ : pyridoxal phosphate; $S A M$ : $S$-adenosylmethionine; (1): methionine adenosyltransferase; (2): various specific methyltransferases; (3): $S$-adenosylhomocysteine hydrolase; (4): 5-methyltetrahydrofolatehomocysteine methyltransferase; (5): cystathionine synthase; (6): cystathionase; $\mathbb{D}$ :serine-hyd roxymethyltransferase. survival after premature birth of man and of the rhesus monkey (16-19). Others consider only the so-called choline pathway of significance in fetal lung (5). The controversy in this field has been reviewed recently (38). It also is possible that biologic methylation would be of importance in the detoxifiction (6) of a number of compounds in the lung.

It was of interest, therefore, to examine the activity of some of the enzymes of the methionine cycle and transsulfuration at times when there might be an increased need for methylation. We find evidence of increased activity of the methionine cycle in the lung during fetal life and evidence that the specific activity of methionine adenosyltransferase in lung increases at the time of gestation when extrauterine life becomes possible for man, monkey, and rabbit.

\section{METHODS AND MATERIALS}

The lungs from previable human fetuses of $3-25 \mathrm{~cm}$ crown-rump length, approximately 6-25 weeks of gestation, were obtained immediately after legal abortion by hysterotomy. None of the investigators participated in any way in the clinical decision for abortion. Gestational age was determined from the crown-rump length nomogram of Tanimura et al. (36). The lungs were removed, freed from any visible blood by washing the pleura with isotonic saline, and immersed in liquid nitrogen. No fetus was observed to breathe after removal from the amniotic sac. Human newborn lungs were obtained from premature and term human newborns who died of causes other than respiratory distress or pulmonary disease, as determined clinically. Biopsies of these lungs were performed through high axillary intercostal incision not later than $2 \mathrm{hr}$ after death. After removal and saline washing, if necessary, these lungs were immersed in liquid nitrogen. Human adult lung was obtained during postmortem examination up to $4 \mathrm{hr}$ after death. Specimens from adults with obvious pulmonary disease were excluded from the study. After freezing in liquid nitrogen, all samples were stored at $-70^{\circ}$ until analyzed (no longer than 2 weeks).

Female rhesus monkeys, weighing 2-3 kg, were obtained pregnant from the wild. They were kept in the Laboratory for Experimental Surgery in Primates, Tuxedo, New York, until operation or delivery. The stage of pregnancy was determined roentgenographically and by palpation with an accuracy of \pm 5 days. Fetuses at various stages of gestation were obtained by cesarian section under Nembutal anesthesia. They were prevented from breathing, if necessary, by capping the head with a condom. Lungs were removed and kept frozen as described above. Lungs were obtained from newly born monkeys delivered vaginally at term. Newborns at various ages were decapitated and the lungs were removed, washed, and frozen.

Pregnant New Zealand albino rabbits were obtained from Perfection Breeders, Douglasville, $\mathrm{Pa}$. The time of conception was known within $6 \mathrm{hr}$. The dams were decapitated at several stages of gestation, the uterus removed, and the lungs of the fetuses quickly removed and immersed in liquid nitrogen. Dissection was performed with the aid of a dissecting microscope, whenever necessary. Newborn rabbits were decapitated at various stages after birth, and the lungs were removed as described.

$\mathrm{L}-\left[3-{ }^{14} \mathrm{C}\right]$ Serine $(48 \mathrm{mCi} / \mathrm{mol})$ was obtained from Amersham/ Searle, Arlington, Ill.; [methyl- $\left.{ }^{14} \mathrm{C}\right]$ betaine was obtained from New England Nuclear, Boston, Mass. All other reagents were of the highest purity available from Sigma Chemical Co., St. Louis, Mo., and were used without purification.

Sample preparation was carried out at $0-4^{\circ}$. Fetal lungs were homogenized in a Potter-Elvehjem glass-glass homogenizer for 4 min in equal parts $(w / v)$ of Tris buffer, $0.2 \mathrm{M}, \mathrm{pH} 7.2$. Mature lungs were first homogenized in an OmniMixer from Sorvall, Inc., Norwalk, Conn., with two parts of buffer (w/v) and then again homogenized in a glass-glass homogenizer. Supernates obtained after centrifugation at $30,000 \times g$ for $1 \mathrm{hr}$ were used for all assays. Activity of methionine adenosyltransferase was determined by 
quantifying the amount of $S$-adenosylmethionine formed under conditions saturating for substrates (13). Except where indicated, the following, in micromoles, were incubated at $37^{\circ}$ for $120 \mathrm{~min}$ in a total volume of $0.5 \mathrm{ml}$ : Tris- $\mathrm{HCl}$ buffer, $\mathrm{pH} 7.2,60 ; \mathrm{KCl}, 80$; $\mathrm{MgCl}_{2}, 120$; ATP, 18; L-methionine, 10. Appropriate dilutions of the tissue extract were made with the same Tris buffer, and the other compounds were added as neutral aqueous solutions. $S$-Adenosylmethionine was quantified with a Beckman model $120 \mathrm{C}$ amino acid analyzer (13). Calculation of the peak area and subsequent calculations were carried out with an Infotronics 1000L on-line computer. Cystathionine synthase and cystathionase were determined by our previously described assays (13). We used our minor modifications (14) of the radioassays for the determination of betaine-homocysteine methyltransferase (8), 5-methyltetrahydrofolate-homocysteine methyltransferase (8), and serine-tetrahydrofolate-methyltransferase (EC. 2.1.1.1) (37). All assays were performed in duplicate; the duplicates did not differ more than $10 \%$. A blank determination with extract boiled for $5 \mathrm{~min}$ before incubation was performed for each sample. Protein was determined by the method of Lowry et al. (21).

\section{RESULTS}

ASSAY CONDITIONS FOR METHIONINE ADENOSYLTRANSFERASE

Optimal conditions for the assay of methionine adenosyltransferase in crude extracts of human fetal lung were systematically determined. Concentrations used for both substrates were saturating; $36 \mathrm{mM} \mathrm{ATP}$ and $20 \mathrm{mM}$ L-methionine give maximal activity. There was no activity without added ATP, whereas without methionine it was about $20 \%$ of the maximal activity. This is similar to rat and human liver $(33,34)$, in which even with partially purified methionine adenosyltransferase there was a considerable activity without added methionine, but none without added ATP.

The activity of methionine adenosyltransferase in human fetal lung was proportional to the concentration of soluble protein when analyzed in the range between 0.8 and $6.8 \mathrm{mg}$ protein/assay in piperazine- $N, N^{\prime}$-bis(2-ethane sulfonic acid) (Pipes) buffer, $0.8 \mathrm{M}$ at $\mathrm{pH}$ 7.0. At low protein concentrations, it was observed that Tris buffer, which was used for the actual determinations of specific activity, caused a slight inhibition resulting in a deviation from linearity. This has been observed previously, but not commented on, by Mudd et al. (22). In our studies $3.0 .6 .0 \mathrm{mg}$ protein were used, which is in the linear range for both buffers.

The activity of methionine adenosylt ransferase in human fetal lung was proportional to the time of incubation at $37^{\circ}$, with an initial time lag of $4 \mathrm{~min}$ when incubated with Tris buffer. This time lag disappeared when the reaction mixture was incubated with Pipes buffer at the same $\mathrm{pH}$, again suggesting a slight inhibition of methionine adenosyltransferase by Tris.

Tris buffer rapidly loses its buffering capacity below pH 7.0. Therefore, we also used Pipes buffer for the determination of $\mathrm{pH}$ optima, after it was established that Pipes does not activate or inhibit methionine adenosylt ransferase in the $\mathrm{pH}$ range over 7.0 . In the $\mathrm{pH}$ curves, the $\mathrm{pH}$ at several points was rechecked after incubation, and it did not differ from the value before incubation by more than $0.02 \mathrm{pH}$ units. The $\mathrm{pH}$ optimum in Pipes buffer for human fetal lung was 6.2-6.4. At pH 7.0, the fetal lung enzyme in vitro was $75 \%$ of its maximal activity. Ault human lung also had a $\mathrm{pH}$ optimum of 6.2-6.4. At $\mathrm{pH} 7.0$ the adult lung enzyme in vitro had $85 \%$ of its maximal activity. Human fetal liver, like human adult liver (35), has a pH optimum at 7.0 (Pipes buffer) with a broad peak. The activity of methionine adenosyltransferase was measured with Tris buffer at $\mathrm{pH} 7.2$ in all lung extracts, since many of our experiments were already done when the $\mathrm{pH}$ optimum of lung was found to be lower than that of liver. Because of the small size of the samples and the difficulty in obtaining the original human samples, it was not possible to repeat the determination for methionine adenosyltransferase in all of them. Thus, the values reported consistently represent about $75 \%$ of the maximal activity.

\section{HUMAN FETAL. LUNG}

In 18 human lungs from first and second trimester fetuses there was an increase in the specific activity of methionine adenosyltransferase with increasing crown-rump length $(r=0.87 ; P<$ 0.01 ) (Fig. 2). In nine newborn human lungs from $9 \mathrm{hr}$ to 25 days of age, methionine adenosyltransferase was $3.05 \pm 1.52 \mathrm{nmol} / \mathrm{mg}$ protein $/ \mathrm{hr}$ (Table 1). No dependence on postnatal age, weight at birth, weeks of gestation, or the time after death of autopsy (within the limit of $2 \mathrm{hr}$ ) was observed. In two adult lungs the activity was 1.3 and $1.6 \mathrm{nmol} / \mathrm{mg}$ protein $/ \mathrm{hr}$, respectively.

5-Methyltetrahydrofolate-homocysteine methyltransferase in 16 fetal human lungs was $2.51 \pm 0.88 \mathrm{nmol} / \mathrm{mg}$ protein $/ \mathrm{hr}$ (Table l). No correlation with crown-rump length was observed. This value was far higher than that found in neonatal and mature lung. It was half the specific activity we reported for fetal liver, but twice that of mature liver (14). Betaine-homocysteine methyltransferase was determined in six fetal (second trimester) human lungs; only a trace of activity was found. Cystathionine synthase was determined in lungs from 5 fetuses, 13 newborns, and 3 adults; only trace activity was found. Cystathionase was determined in lungs from 5 fetuses and 13 newborns; it was found to have a specific activity approaching the lower limit of detection in our assay. In contrast to neonatal liver, in which the specific activity of cystathionase and cystathionine synthase increased after birth, there was no postnatal increase. Serine hydroxymethyltransferase was determined in 15 fetal lungs; the specific activities approached the lower limit of detection.

\section{RHESUS MONKEY FETAL LUNG}

Because of the uncertainties of interpretation when postmortem human tissues are utilized, the lack of availability of third

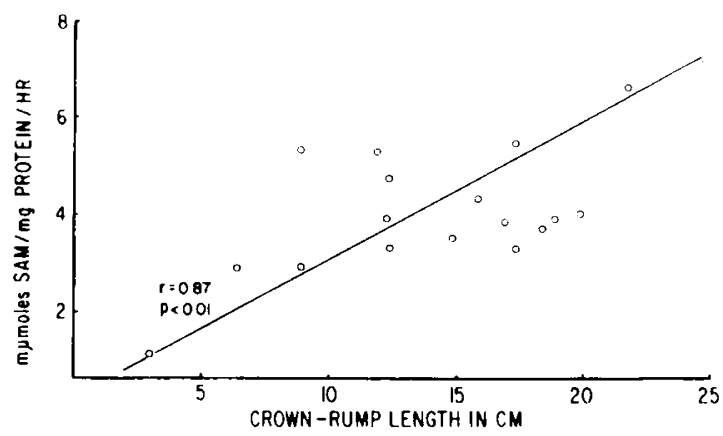

Fig. 2. Development of specific activity of methionine adenosyltransferase in human lung. $S A M: S$-adenosylmethionine.

Table 1. Enzymatic activities in human lung and liver ${ }^{1}$

\begin{tabular}{lcc} 
& $\begin{array}{c}\text { Methionine } \\
\text { adenosyltransferase }\end{array}$ & $\begin{array}{c}\text { 5-Methyltetrahy- } \\
\text { drofolate- } \\
\text { homocysteine } \\
\text { methyltransferase }\end{array}$ \\
\hline Fetal lung & 2 & $2.51 \pm 0.88^{3}(16)$ \\
Newborn lung & $3.05 \pm 1.52(9)$ & $0.14 \pm 0.01(6)$ \\
Mature lung & $1.30 ; 1.60$ & $0.10 ; 0.05$ \\
Fetal liver & $26 \pm 3(24)$ & $4.70 \pm 0.16(31)$ \\
Mature liver & $86 \pm 16(9)$ & $1.30 \pm 0.20(17)$
\end{tabular}

${ }^{1}$ All values are nanomoles of product formed per $\mathrm{mg}$ of soluble protein per $\mathrm{hr} \pm$ standard error. Numbers in parentheses indicate number of specimens studied.

${ }^{2}$ Increase in specific activity with increasing crown-rump length (Fig. 2).

${ }^{3} P<0.001$ by Student unpaired $t$-test when compared with newborn lung.

- Values are taken from References 12 and 14 and presented for ease of comparison. 
trimester human fetuses and of normal human newborns, and because of the similarity of the human to the monkey with regard to the metabolism of the lung (15) and development of sulfur amino acid metabolism (32), we examined the development of these enzymes in monkey lung. Methionine adenosyltransferase was determined in the lungs of 21 monkeys: 12 fetuses from 100 days to 155 days of gestation and 9 infants from 1 hr to 1 year of age. Term in the monkey is about 165 days. Lungs from fetuses obtained between 100 and 145 days of gestation have relatively low specific activity, $1.36 \mathrm{nmol} / \mathrm{mg}$ protein $/ \mathrm{hr} \pm 0.68$. No correlation with gestational age could be demonstrated (Table 2). Immediately before term, however, the specific activity increases almost 6-fold During the first weeks of life it gradually diminishes over a period of 3 months to reach the specific activity found in adult lung. One fetus, delivered by cesarian section on day 142 of gestation, was accidentally allowed to breathe for about $5 \mathrm{~min}$. In this lung, the specific activity of methionine adenosyltransferase was found to be about 3 times higher than that of fetuses of this age that had not breathed. 5-Methyltetrahydrofolate-homocysteine methyltransferase activity was $6.57 \pm 0.95 \mathrm{nmol} / \mathrm{mg}$ protein $/ \mathrm{hr}$ in fetal monkey lungs and $1.91 \pm 0.97$ in lungs from newborns. This difference was statistically significant $(P<0.001)$. These values were similar to those found in fetal and mature liver of this animal (Table 2).

\section{RABBIT FETAL LUNG}

A total of 44 litters, with an average of 8 fetuses, and 12 adult rabbit lungs were analyzed for activity of methionine adenosyltransferase. The specific activity decreases from $5.14 \pm 0.70$ $\mathrm{nmol} / \mathrm{mg}$ protein $/ \mathrm{hr}$ on the $18 \mathrm{th}$ day of pregnancy to $2.03 \pm 0.58$ $\mathrm{nmol} / \mathrm{mg}$ protein/hr on the last day of pregnancy (day $3 \mathrm{l}$ ). After birth, the activity increases during the first $48 \mathrm{hr}$ of extrauterine life to a maximum of $4.13 \pm 0.63 \mathrm{nmol} / \mathrm{mg}$ protein $/ \mathrm{hr}$ (Fig. 3). Lungs from one litter were analyzed when the pups were $72 \mathrm{hr}$ of age and were even higher, $5.9 \mathrm{nmol} / \mathrm{mg}$ protein $/ \mathrm{hr}$. Mean specific activity in the adult lung, as determined in 12 dams, was $1.49 \pm$ $0.10 \mathrm{nmol} / \mathrm{mg}$ protein $/ \mathrm{hr}$, which was significantly lower than the mean specific activity at birth $(P<0.05)$. Although female rat liver has a higher specific activity of methionine adenosyltrans-

Table 2. Enzymatic activities in rhesus monkey lung and liver ${ }^{1}$

\begin{tabular}{|c|c|c|c|}
\hline & & $\begin{array}{l}\text { Methionine } \\
\text { adenosyltrans- } \\
\text { ferase }\end{array}$ & $\begin{array}{c}\text { 5-Methyltetrahy- } \\
\text { drofolate- } \\
\text { homocysteine } \\
\text { methyltransferase }\end{array}$ \\
\hline \multicolumn{4}{|l|}{ Fetal lung } \\
\hline $100-145$ days & (11) & $1.36 \pm 0.68^{2}$ & $6.57 \pm 0.95^{2}$ \\
\hline 142 days, breathing & (1) & 3.84 & 3.79 \\
\hline 158 days & (2) & $8.53 ; 8.89$ & $3.34 ; 5.76$ \\
\hline \multicolumn{4}{|l|}{ Neonatal lung } \\
\hline $1 \mathrm{hr}$ & (2) & 6.29 & \\
\hline 7 days & (1) & 8.93 & \\
\hline 9 days & (1) & 5.35 & \\
\hline 30 days & (i) & 4.28 & $1.91 \pm 0.97(9)$ \\
\hline 110 days & (1) & 3.36 & \\
\hline 168-370 days & (3) & $1.63 \pm 0.05$ & \\
\hline $\begin{array}{l}\text { Fetal liver }{ }^{3} \\
\text { (145-160 days of } \\
\text { gestation) }\end{array}$ & (7) & $93.1 \pm 12.5$ & $6.41 \pm 0.52$ \\
\hline Mature liver ${ }^{3}$ & (17) & $251.9 \pm 50.8$ & $2.58 \pm 0.18$ \\
\hline
\end{tabular}

${ }^{1}$ All values are nmoles of product formed per $\mathrm{mg}$ of soluble protein per hour \pm standard error. Numbers in parentheses indicate number of specimens studied.

${ }^{2} P<0.001$ by Student unpaired $t$-test when compared with values from 5 days before to 110 days after birth.

${ }^{3}$ Values are taken from unpublished studies by J. A. Sturman and G. E. Gaull (29) and are given for the purpose of comparison with lung.

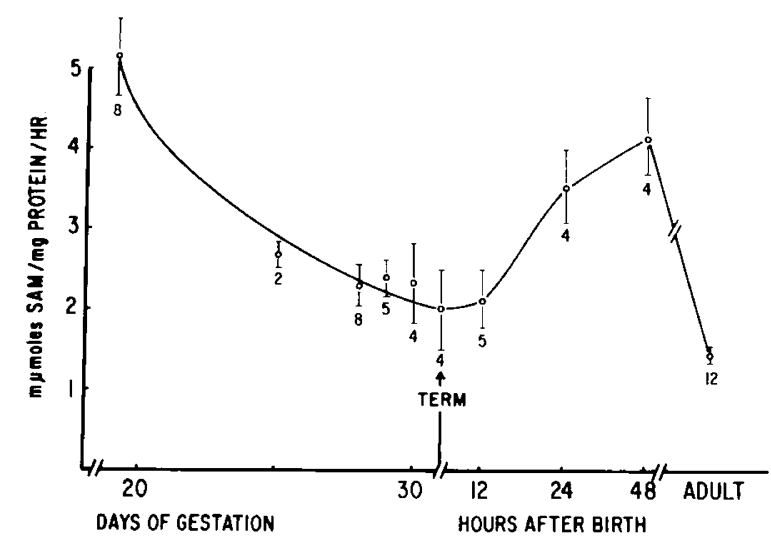

Fig. 3. Development of specific activity of methionine adenosyltransferase in rabbit lung. The number under each point is the number of litters examined at each age or the number of individual dams. See text for details. $S A M$ : $S$-adenosylmethionine.

ferase than male rat liver (23), this is not true in the rabbit (20); therefore, lungs from male rabbits were not studied.

\section{DISCUSSION}

The present data give evidence of increased activity of the methionine cycle in fetal lung. Methionine adenosyltransferase activity is increased at a time when 5-methyltetrahydrofolate methyltransferase activity is also increased and when activities of cystathionine synthase and cystathionase are absent. The increase in the methyltransferase (with its apparent $\mathrm{K}_{\mathrm{m}}$ for homocysteine of $10^{-5} \mathrm{M}$ ), combined with the virtual absence of both enzymes of transsulfuration, would assure maximal recycling of homocysteine sulfur to methionine sulfur and transfer of the methyl group of 5 -methyltetrahydrofolate for resynthesis of $S$-adenosylmethionine. Maximal methylation capability would then be assured. The question might be posed: Why should there be any increase in specific activity of methionine adenosyltransferase when it is known to be operating at substrate concentrations well below its $\mathrm{K}_{\mathrm{m}}$ for methionine? However, if there should be an increased demand for $S$-adenosylmethionine at such times in development when the concentration of methionine in the tissues actually is decreasing, an increase in total methionine adenosyltransferase activity might be necessary to provide the enzymatic capacity required to meet this increased demand. The mechanism for regulation of methionine adenosyltransferase activity appears to be complex $(4,34)$, suggesting that it may be involved in regulatory functions and demonstrating that factors other than substrate concentration are important.

The increasing specific activity of methionine adenosyltransferase activity in the lung of the human, monkey, and rabbit around the time when each species acquires the respiratory capability to survive is striking. A change in composition of the blood perfusing the lungs at this time might elicit such an increase, since methylation reactions may be involved in the detoxification of both endogenous and exogenous substances (6). It is also possible that the increase in the enzymatic potential for methylation might be related to the respiratory function of the lung.

Human and monkey fetuses have the respiratory capability to survive premature birth by the dint of the ability to synthesize surfactants prior to term. In both species, around the time that survival becomes possible (at about 28 weeks for the human; at about $150-155$ days for the monkey, with about $50 \%$ survival at 145 days (24)), the activity of methionine adenosyltransferase increases (Fig. 4). In the monkey, there is a perinatal peak of activity which begins about 2 weeks before term, which is just the time that Gluck and coworkers (15) have reported the lecithin to sphingomyelin ratio of the amniotic fluid in the monkey to rise. I the human, there is a steady increase in specific activity during the 


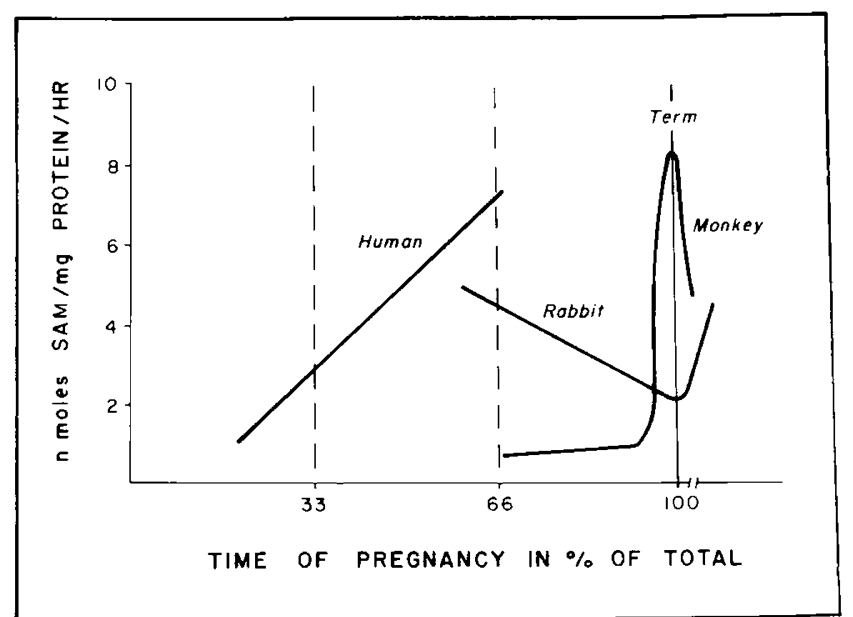

Fig. 4. Comparison of development of specific activity of methionine adenosyltransferase in lung from human, monkey, and rabbit with regard to the time of pregnancy. $S A M: S$-adenosylmethionine.

second trimester. Third trimester human fetuses and normal human neonates cannot be studied; however, the similarity of the monkey to the human with regard to other aspects of sulfur metabolism (32) suggests that the increase occurring during the second trimester probably continues into the third trimester. The mean specific activity of lung methionine adenosyltransferase of the human neonate is below the specific activity late in the second trimester but probably above that in mature lung. It also is possible that the specific activity was lower in neonatal lung than in the fetal lung in our study because the neonates all had been sick prior to death or because the enzyme is unstable postmortem. Zachman (40) also reported methionine adenosyltransferase activity in lungs obtained postmortem from newly born infants, but he used a different assay, and it is not clear that his results are comparable with ours. One major discrepancy between his results and ours is that he found methionine adenosyltransferase activity in neonatal lung higher than in neonatal liver, whereas we found liver at all stages of development to have a higher specific activity than lung. No explanation of this discrepancy is apparent to us. Rabbits cannot breathe prior to 1 or 2 days before term. In the rabbit fetus, in contrast to the human fetus and to the monkey fetus, there is a decrease in specific activity of methionine adenosyltransferase in later stages of gestation (Fig. 4). At term, when survival for the rabbit is possible, the activity of lung methionine adenosyltransferase also increases.

There are two pathways for synthesis of phosphatidylcholine (lecithin): (l) the choline pathway which requires preformed choline and which has not been shown to require $S$-adenosylmethionine; (2) the methylation pathway in which 3 molecules of $S$-adenosylmethionine are required for each molecule of phosphatidylcholine synthesized (38). Gluck and coworkers (16-19) have provided indirect data in support of their hypothesis that in the human fetus from 22 to 35 weeks of gestation it is the methylation pathway that is involved in the de novo synthesis of surfactant lecithin (phosphatidylcholine); beginning at 35 weeks the choline pathway becomes quantitatively important. There is considerable disagreement about the importance of the methylation pathway $(5,38)$. The present results are consistent with the proposed existence of the methylation pathway in human and monkey fetal lung, although they do not establish its existence or its quantitative significance. The recent work of Salerno and Beeler (27) raises the possibility that $S$-adenosylmethionine also may play a role in the choline pathway for the synthesis of phosphatidylcholine. $S$-Adenosylmethionine has been known to be the methyl donor during the methylation of phosphatidylethanolamine to phosphatidylcholine ("methylation pathway") $(1,39)$. Salerno and Beeler showed rapid incorporation of $\left[\right.$ methyl $\left.-{ }^{3} \mathrm{H}\right]$ methionine in vivo into choline and phosphorylcholine and proposed that $S$-adenosylmethionine is the methyl donor for the methylation of ethanolamine, phosphorylethanolamine, and probably CDP-ethanolamine, as well as of phosphatidylethanolamine. If their work is correct and if it applies to lung, then it is possible that the increase in specific activity of methionine adenosyltransferase, and, therefore, in availability of $S$-adenosylmethionine, is involved in synthesis of phosphatidylcholine by either or by both routes.

\section{SUMMARY}

Methionine adenosyltransferase activity in lung is increased at a time when 5-methyltetrahydrofolate methyltransferase activity is also increased and when activities of cystathionine synthase and cystathionase are absent. Maximal enzymatic capability is found in the lung of the human, monkey, and rabbit around the time when each species acquires the respiratory capacity to survive.

\section{REFERENCES AND NOTES}

1. Bremer, J., Figard, P. H., and Greenberg, D. M.: The biosynthesis of choline and its relation to phospholipid metabolism. Biochim. Biophys. Acta, 43: 477 (1960).

2. Cantoni, G. L.: S-Adenosylmethionine: A new intermediate formed enzymatically from $L$-methionine and adenosine triphosphate. J. Biol. Chem., 204: 403 (1953)

3. Chase, H. P., Volpe, J. J., and Laster, L.: Transsulfuration in mammals: Fetal and early development of methionine-activating enzyme and its relation to hormonal influences. J. Clin. Invest., 47: 2009 (1968).

4. Chou, T.-C., and Talalay, P.: The mechanism of $S$-adenosyl-L-methionine synthesis by purified preparations of bakers' yeast. Biochemistry, 11: 1065 (1972).

5. Farrell, P. M., Lundgren, D. W., and Adams, A. J.: Choline kinase and choline phosphotransferase in developing fetal rat lung. Biochem. Biophys. Res. Commun., 57: 696 (1974).

6. Feuer, G., Miller, D. R., Cooper, S. D., de la Eglesia, F. A., and Lumb, G.: The influence of methyl groups on toxicity and drug metabolism. Int. J. Clin. Pharmacol. Ther. Toxicol., 7: 13 (1973-1).

7. Finkelstein, J. D. Methionine metabolism in mammals. In: N. A. J. Carson and D. N. Raine: Inherited Disorders of Sulphur Metabolism (Churchill Livingstone, London, 1971).

8. Finkelstein, J. D., Kyle, W. E., and Harris, B. J.: Methionine metabolism in mammals: Regulation of homocysteine methyltransferase in rat tissues. Arch. Biochem. Biophys., 146: 84 (1971).

9. Finkelstein, J. D., and Mudd, S. H.: Transsulfuration in mammals. The methionine-sparing effect of cystine. J. Biol. Chem., 242: 873 (1967)

10. Gaull, G. E.: Interrelationships of sulfur amino acids, folate and DNA in human brain development. F. Hommes and C. J. von den Berg: Symposium on Development Biochemistry-Inborn Errors of Metabolism. (Academic Press, New York, 1973).

11. Gaull, G. E.: Sulfur amino acids, folate, and DNA: Metabolic interrelationships during fetal development. Proceedings of the Sir Joseph Barcroft Centenary Symposium (Cambridge University Press, Cambridge, 1973).

12. Gaull, G. E., Sturman, J. A., and Räihä, N. C. R.: Development of mammalian sulfur metabolism: Absence of cystathionase in human fetal tissue. Pediat. Res., 6: 538 (1972).

13. Gaull, G. E., Sturman, J. A., and Rassin, D. K.: Enzymatic and metabolic studies of homocystinuria: Effects of pyridoxine. Neuropadiatrie, $1: 199$ (1969).

14. Gaull, G. E., von Berg, W., Räihä, N. C. R., and Sturman, J. A.: Development of methyltransferase activities of human fetal tissues. Pediat. Res., 7: 527 (1973)

15. Gluck, L., Chez, R., Kulovich, M. V., Hutchinson, D. L., and Niemann, W. H. Comparison of phospholipid indicators of fetal lung maturity in the amniotic nuid of the monkey (Macaca mulatta) and baboon (Papio papio). Amer. J. Obstet. Gynecol., 120: 524 (1974).

16. Gluck, L., Kulovich, M., Eidelman, A. I., Cordero, L., and Khazin, A. F.: Biochemical development of surface activity in mammalian lung. IV. Pulmonary lecithin synthesis in the human fetus and newborn and etiology of the respiratory distress syndrome. Pediat. Res., 6: 81 (1972).

17. Gluck, L., Landowne, R. T., and Kulovich, M.: Biochemical development of surface activity in mammalian lung. III. Structural changes in lung lecithin during development of the rabbit fetus and newborn. Pediat. Res., 4: 353 (1970).

18. Gluck, L., Motoyama, E. K., Smits, H. L., and Kulovich, M. V.: The biochemical development of surface activity in mammalian lung. I. The surface active phospholipids; the separation and distribution of surface-active lecithin in the lung of developing rabbit fetus. Pediat. Res., $l: 237$ (1967).

19. Gluck, L., Schribney, M., and Kulovich, V.: The biochemical development of surface activity in mammalian lung: The biosynthesis of phospholipids in the lung of the developing rabbit fetus and newborn. Pediat. Res., I: 247 (1967).

20. Hancock, R. S-Adenosylmethionine-synthesizing activity of normal and neoplastic mouse tissues. Cancer Res., 26: 2425 (1966-1).

21. Lowry, O. H., Rosebrough, N. J., Farr, A. L., and Randall, R. J.: Protein measurement with the Folin phenol reagent. J. Biol. Chem., 193: 265 (195!). 
22. Mudd, S. H., Finkelstein, J. D., Irreverre, F., and Laster, L.: Transsulfuration in mammals: Microassays and tissue distribution of three enzymes of the pathway. J. Biol. Chem., 240: 4382 (1965).

23. Natori, Y.: Studies on ethionine. VI. Sex-dependent behavior of methionine and ethionine in rats. J. Biol. Chem., 238: 2075 (1963).

24. Niemann, W.: Unpublished observations.

25. Pascal, T. A., Gillam, B. M., and Gaull, G. E.: Cystathionase: Immunochemical evidence for absence from human fetal liver. Pediat. Res., 6: 773 (1972)

26. Rose, W. C., and Wixom, R. L.: Amino acid requirements of man. XIII. Sparing effect of cystine on the methionine requirement. J. Biol. Chem., 216:95 (1955).

27. Salerno, D. M., and Beeler, D. A.: The biosynthesis of phospholipids and their precursors in rat liver involving de novo methylation, and base-exchange pathways, in vivo. Biochim. Biophys. Acta, 326: 325 (1973).

28. Sturman, J. A., and Gaull, G. E.: Polyamine biosynthesis in human fetal liver and brain. Pediat. Res., 8: 321 (1974).

29. Sturman, J. A., and Gaull, G. E.: Unpublished studies.

30. Sturman, J. A., Gaull, G., and Räihä, N. C. R.: Absence of cystationase in human fetal liver: Is cystine essential? Science, 169: 74 (1970).

31. Sturman, J. A., Gaull, G. E., and Räihä, N. C. R.: DNA synthesis from the $\beta$-carbon of serine by fetal and mature human liver. Biol. Neonate, 27: 17 (1975).

32. Sturman, J. A., Niemann, W. H., and Gaull, G. E.: Metabolism of ${ }^{35}$ S-methionine and ${ }^{35} \mathrm{~S}$-cystine in the pregnant Rhesus monkey. Biol. Neonate, 21: 16 (1973)

33. Tallan, H. H.: Unpublished observations.

34. Tallan, H. H., Cohen, P. A., and Gaull, G. E.: Allosteric properties of rat liver methionine-activating enzyme. Fed. Proc., 31: 576 (1973).

35. Tallan, H. H., and Gaull, G. E.: Unpublished data.

36. Tanimura, T., Nelson, T., Hollingworth, R. R., and Shepard, T. H. Weight standards for organs from early human fetuses. Anat. Rec., 171. 227 (1971).

37. Taylor, R. T., and Weissbach, H.: Radioactive assay for serine transhydroxymethylase. Anal. Biochem., 13: 80 (1965).

38. Villee, C. A., and Villee, D. B.: Respiratory Distress Syndrome Conference Proceedings (Academic Press, New York, 1973).

39. Wilson, J. D., Gibson, K. D., and Udenfriend, S.: Studies on the precursors of methyl groups of choline in rat liver. J. Biol. Chem., 235: 3213 (1960).

40. Zachmann, R. D.: The enzymes of lecithin biosynthesis in human newborn lungs. II. Methionine-activating enzyme and phophatidyl methyltransferase. Biol. Neonate, 20: 448 (1972)

41. We are grateful to Dr. Wendell Niemann for determination of gestational age in the monkeys. Mrs. Susan Sansevero gave expert technical assistance.

42. Dr. Sternowsky, on leave from the University of Hamburg. Pediatric Clinic, was the recipient of a grant from the Deutsche Forschungsgemeinschaft, Bad Godesberg.

43. This study was supported by the New York State Department of Mental Hygiene National Institutes of Health Clinical Genetics Center Grant GM-19443, and the Sigrid Juselius Foundation.

44. Requests for reprints should be addressed to: G: Gaull, M.D., Department of Pediatric Research, New York State Institute for Basic Research in Mental Retardation, 1050 Forest Hill Rd., Staten Island, N.Y. 10314 (USA).

45. Aci epted for publication December 3, 1975.

\title{
Type I Hyperprolinemia: A Study of the Intestinal Absorption of Proline, Hydroxyproline, and Glycine
}

\author{
J. P. FARRIAUX ${ }^{(17)}$ AND J. L. DHONDT \\ Laboratoire de Recherche, Clinique Pédiatrique, Cité Hospitalière, Lille, France
}

\section{Extract}

Intestinal absorption of proline, hydroxyproline, and glycine was interpreted by investigation of a type I hyperprolinemia patient and six control subjects. Intestinal perfusion was performed.

When proline (Pro), hydroxyproline (OH-Pro), and glycine (Gly) were infused together, an increase in proline concentration did not alter aminoacid uptake in the control subjects; however, in the hyperprolinemia patient, uptake of aminoacids became negligible (Pro, 17-6 $\mu \mathrm{M} / \mathrm{min}$; OH-Pro, 15-0.3 $\mu \mathrm{M} / \mathrm{min}$; and Gly, 13.5-0 $\mu \mathrm{M} / \mathrm{min}$ ).

When each aminoacid was infused alone at increasing concentrations aminoacid uptake increased in controls; in the hyperprolinemic patient, intestinal absorption was less for glycine and hydroxyproline but aminoacid uptake increased with substrate concentration; however, for proline, the uptake remained constant (16.5-17 $\mu \mathrm{M} / \mathrm{min} / \mathbf{2 0} \mathrm{cm}$ of intestinal test segment) (Table 1 ).

When hydroxyproline was infused with an increased concentration of proline in the hyperprolinemic patient, hydroxyproline uptake first increased $(9.8-14.3 \mu \mathrm{M} / \mathrm{min} / 20 \mathrm{~cm})$ then decreased to its basal value, whereas, in the control subjects, uptake increased without decreasing subsequently.

\section{Speculation}

The chronic hyperprolinemia state might entail adaptation of the transport mechanism with the three infused aminoacids (Pro, OH-Pro, and Gly), bringing about an "overflow" of the system similar to that observed in the kidney. However, the inhibition of intestinal iminoacids and glycine transport seems to be due to mechanisms more complex than that of a simple inhibition by proline.

The mechanisms of membrane transport of proline, hydroxyproline, and glycine have been investigated in some recent studies, the results of which seem to indicate the presence, in vivo, of a single transport system for iminoacids and glycine $(7,10,11,13)$.

Investigation of a type I hyperprolinemia patient allowed us to suggest a new approach to the problems of intestinal absorption of these three aminoacids.

\section{EXPERIMENTAL PROCEDURE}

\section{SUBJECTS}

The subjects were one patient with type I hyperprolinemia whose case is described in an earlier report (4) and six control subjects of the same age and weight as the propositus; none had evidence of small bowel or metabolic diseases and plasma aminoacid levels (Pro, Gly, OH-Pro) were normal.

\section{METHODS}

A method of intestinal perfusion with which we were already familiar was adopted (3). 